\title{
MODEL KEMITRAAN DALAM PEMBANGUNAN RUMAH SEWA SWADAYA
}

\author{
Sigit Wijaksono \\ Architecture Department, Faculty of Engineering, Binus University \\ Jl. K.H. Syahdan No. 9, Palmerah, Jakarta Barat 11480 \\ swijaksono@binus.edu
}

\begin{abstract}
The high prices of land causes the decreasing development of rental housing around activity centers such as workplaces, schools and others. The specific objective of this study is to identify and map the forms of existing partnerships between government, business, and community organizations in the construction of rental housing, to identify obstacles in the implementation and effectiveness of these partnerships, and to develop a partnership model that can include and involve all interests (stakeholders) either from the government (central or local), businesses, and communities, as well as their respective roles in realizing the construction of rental housing for low income community. This study implements is a qualitative method with exploratory descriptive and comparative approach. Data are obtained through surveys in several locations as representatives of existing forms of self-help construction of rental housing in Jakarta, West Java and Batam. Data collection technique used observation and interviews are supported by direct observation in the field. The model developed is aimed at promoting self-help development of affordable rental housing which involves a partnership among government, business, and society. The partnership should be beneficial to all three parties. It should also allow affordability of low-income community to rent the house in the form of licensing component funded by national and local government, construction financed by the business or government, while the land acquisition component can use the land the community or local government.
\end{abstract}

Keywords: partnership, self-help rental housing, government, business, low income community

\begin{abstract}
ABSTRAK
Mahalnya harga tanah merupakan salah satu unsur penyebab tidak berkembangnya pembangunan rumah sewa di sekitar pusat-pusat kegiatan seperti tempat kerja, sekolah dan lain sebagainya. Untuk itu dibutuhkan suatu bentuk kemitraan agar dapat memecahkan masalah ini. Tujuan khusus dari penelitian ini adalah untuk mengidentifikasikan dan memetakan bentuk-bentuk kemitraan yang telah ada antara pemerintah, dunia usaha, dan masyarakat dalam pembangunan rumah sewa swadaya, mengidentifikasikan efektifitas dan kendala dalam pelaksanaan kemitraan tersebut, mengembangkan model kemitraan yang dapat mencakup dan melibatkan semua kepentingan (stakeholder) baik dari pihak pemerintah (pusat atau daerah), dunia usaha, dan masyarakat, serta perannya masing-masing di dalam mewujudkan pembangunan rumah sewa bagi kelompok masyarakat berpenghasilan rendah (MBR). Penelitian ini menggunakan metode kualitatif dengan pendekatan deskriptif eksploratif dan komparatif. Untuk pengumpulan datanya menggunakan metode survei dengan memilih beberapa lokasi sebagai sampel penelitian yang dianggap dapat mewakili berbagai bentuk pembangunan rumah sewa swadaya yang ada, yaitu di wilayah Jabotabek, Jawa Barat, dan Batam. Teknik pengumpulan datanya menggunakan wawancara didukung dengan pengamatan dan peninjauan langsung dilapangan. Model yang dapat dikembangkan bertujuan untuk meningkatkan percepatan pembangunan rumah sewa swadaya yang terjangkau oleh masyarakat berpenghasilan rendah dengan melibatkan pihak pemerintah, dunia usaha, dan masyarakat (kemitraan). Kemitraan ini menguntungkan bagi ketiga pihak. Selai itu, memungkinkan keterjangkauan masyrakat berpenghasilan rendah untuk dapat menyewa rumah tersebut dalam bentuk komponen perijinan dibiayai pemerintah pusat dan daerah, pembangunan konstruksi dibiayai oleh dunia usaha atau pemerintah Pusat atau daerah, sedangkan komponen pengadaan tanah dapat menggunakan tanah milik masyarakat atau pemerintah daerah.
\end{abstract}

Kata kunci: kemitraan, rumah sewa swadaya, pemerintah, dunia usaha, masyarakat berpenghasilan rendah (MBR) 


\section{PENDAHULUAN}

Semakin langka dan mahalnya tanah di perkotaan membuat pembangunan perumahan baru layak huni bagi masyarakat berpenghasilan rendah cenderung menjauh dari tempat kerja (urban sprawl). Keadaan ini menimbulkan ketidakteraturan penataan ruang dan kawasan, permasalahan mobilitas manusia dan barang, beban investasi dan operasi dan pemeliharaan Prasarana Sarana, dan Utilitas (PSU), penurunan produktifitas kerja, serta berdampak buruk terhadap kondisi sosial dan lingkungan.

Dilihat dari pihak pemerintah, penyediaan rumah bagi warganegeranya merupakan tanggung jawabnya, di pihak dunia usaha, mereka membutuhkan tempat tinggal bagi para pekerjanya agar mereka dapat hidup tenang dan berkecukupan sedangkan di pihak masyarakat di bagi dua yaitu pengguna rumah, mereka dapat tinggal di tempat yang layak, dan bagi pemilik lahan yang berada di sekitar kegiatan industri tersebut, mereka dapat mengembangkan usahanya dalam bentuk penyediaan rumah sewa yang terjangkau dan berkualitas. Namun mereka mengalami kesulitan untuk mendapatkan dukungan dari berbagai pihak dalam proses pembangunannya.

Para pengembangan rumah (Developer) tidak merasa tertantang untuk membangun rumah sewa yang dikarenakan untuk mendapatkan lahan tanah developer harus membiayai sendiri, harga tanah yang selalu meningkat, pengurusan ijin yang sangat birokrasi, dan biaya pengurusan ijin yang cukup mahal (ijin pemanfaatan ruang, ijin lokasi, sertifikasi tanah, dan ijinmendirikan bangunan); beban pajak; keterbatasan dukungan prasarana, sarana, dan utilitas (PSU); serta masih tingginya beban bunga pinjaman.

Berdasarkan kondisi di atas, perlu dikembangkan model pembangunan rumah sewa berbasiskan kemitraan guna mengatasi kebutuhan rumah bagi masyarakat berpenghasilan rendah, membantu pemerintah dalam menyelesaikan kebutuhan rumah bagi masyarakat berpenghasilan rendah, dan meningkatkan peran masyarakat dalam mendukung program pemerintah. Terbatasnya daya beli masyarakat khususnya yang berpenghasilan menengah-bawah, terbatasnya penyediaan uang muka, rendahnya kemampuan meminjam akibat tenor pinjaman yang pendek merupakan salah satu alasan harus dikembangkannya model rumah sewa berbasiskan kemitraan.

Menurut Parenta, $\mathrm{W}$ dari USAID, definisi kemitraan pemerintah, dunia usaha, dan masyarakat adalah "an agreement or contract, between a public entity and a private party, under which: (a) private party undertakes government function for specified period of time, (b) the private party receives compensation for performing the function, directly or indirectly, (c) the private party is liable for the risks arising from performing the function and, (d) the public facilities, land or other resources may be transferred or made available to the private party." Jika diterjemahkan dapat berarti perjanjian atau kontrak, antara badan publik dan pihak swasta, di mana: (a) pihak swasta menyanggupi fungsi pemerintah untuk periode waktu tertentu, (b) pihak swasta menerima kompensasi untuk melakukan fungsi, secara langsung atau tidak langsung, (c) pihak swasta bertanggung jawab atas risiko yang timbul dari menjalankan fungsi dan, (d) fasilitas umum, tanah atau sumber daya lainnya dapat ditransfer atau dibuat tersedia untuk pihak swasta.

Penelitian yang dilakukan oleh oleh Universitas Petra Surabaya memperlihatkan bahwa dalam pembangunan Rusunawa dapat dikelompokan dalam tiga pola utama: (1) pola UPT - pembangunan dengan pola ini dilakukan dengan menggunakan dana Pemerintah Daerah (APBD), yang tidak mengharapkan adanya pengembalian investasi, lebih mengarah kepada tujuan sosial. Proyek ini akan menjadi asset daerah dan pengelolaannya diserahkan kepada UPT terkait; (2) pola penyertaan modal pemerintah - pola ini menggunakan dana Pemerintah pusat dan pelaksanaannya diserahkan kepada Pemerintah Daerah. Tanah dan bangunan keseluruahn diserahkan kepada Pemerintah Daerah dan 
didaftarkan sebagai IKMN; (3) pola kemitraan - pola ini merupakan kerjasama dari berbagai pihak dalam mewujudkan pembangunan Rusunawa, yang umumnya melibatkan pihak swasta, industri maupun perbankan. Pola-pola yang dikembangkan meliputi: (1) Pemerintah Kota/ Kabupaten Pemilik Tanah - Kreditur; (2) Pemerintah Kota/ Kabupaten - Kelompok Pemilik Tanah - Kreditur; (3) Pemerintah Kota/ Kabupaten - Kelompok Pemilik Tanah - Perusahaan - Kreditur; (4) Pemerintah Kota/ Kabupaten - Swasta - Kreditur; (5) Pemerintah Kota/ Kabupaten - Swasta + Perusahaan Kreditur.

Adapun bentuk-bentuk kemitraan meliputi: (1) BOO : Build Own Operate, Swasta membangun, memiliki dan mengoperasikan fasilitas yang dikontrakan; (2) BOOT: Build Own Operate Transfer, Swasta membangun, memilki, mengoperasikan dan menyerahkan kepada pemerintah di akhir kontrak; (3) BOT: Built Operate Transfer, Swasta membangun, mengoperasikan dan menyerahkan diakhir kontrak kepada Pemerintah; (4) BTO: Build Transfer Operate, Swasta membangun, menyerahakan diawal kontrak kepada Pemerintah dan mengoperasikannya; (5) DB: Design Build, Swasta membuat design dan membangun sebagai alternative model procurement; (6) DBFO: Design, Build, Finance, Operate. Swasta mendesain, membangun, membiayai dan mengoperasikan; (7) KSO: Kerja Sama Operasi

Terkait dengan judul dan keterbatasan waktu, dalam penelitian ini, peneliti lebih memfokuskan pada aspek kelembagaan, sementera aspek lainnya diteliti pada penelitian lanjutan. Tujuan umum jangka panjang dari penelitian ini adalah mengembangkan sebuah model Pembangunan Rumah Sewa yang berbasis kemitraan antara pemerintah, dunia usaha dan masyarakat.

Tujuan khusus penelitian ini adalah: (1) memetakan bentuk model kemitraan pembangunan rumah sewa yang berjalan; (2) menyiapkan rencana pembangunan kemitraan antara pemerintah, dunia usaha dan masyarakat.yang mencakup rencana investasi, dan bentuk pengelolaan khususnya rumah sewa untuk Masyarakat Berpenghasilan Rendah (MBR); (3) mengembangkan pola-pola kemitraan yang dapat mencakup kepentingan-kepentingan yang ada sehingga dunia usaha dan masyakarat dapat berperanserta seluas-luasnya dalam kemitraan pembangunan

\section{METODE}

Penelitian dibagi menjadi dua tahap. Pada tahap pertama, metode penelitian yang digunakan adalah sebagai berikut: penelitian survei, survei di lakukan di Jakarta, Tangerang dan Bandung.dengan fokus pada rumah sewa yang berbasiskan kemitraan di 5 lokasi. Pemetaan model-model rumah sewa untuk MBR saat ini baik yang bermitra maupun yang tidak bermitra. Di tahap kedua, peneliti melakukan survei ke industri (tempat MBR bekerja). Survey bertujuan untuk mendapatkan data mengenai: Apakah industri memiliki program CSR? Jika ada, apakah ada yang berhubungan dengan bidang perumahan, Jika ya, di bidang perumahan seperti apa? Bagaimana industri menyisihkan atau mendistribusikan untuk bidang perumahan? Bagaimana modelnya? Keterlibatan industri dimaksudkan untuk melihat, apakah memungkinkan dana CSR dimasukan sebagai bagian dari model subsidi rumah sewa bagi masyarakat berpenghasilan rendah.

\section{HASIL DAN PEMBAHASAN}

Pada penelitian tahap 1, survei dilakukan di lima tempat, yaitu: Perumahan Bukit Tiara (Kawasan industri Jatake), Kawasan Industri Manis (Tangerang), Jamsostek (Muka Kuning, Batam), Rumah susun sewa Pondok Bambu, dan Rumah susun sewa Cigugur - Cimahi. 


\section{Bukit Tiara Mutiara, Daerah kawasan industri Jatake}

Pada perumahan Bukit Tiara penyediaan lahan tanah dilakukan oleh PT Gajah Tunggal dengan cara membeli terlebih dahulu, lalu pembangunannya dilakukan kerja sama dengan developer. Perumahan tersebut diperuntukan bagi para karyawan Gajah Tunggal dengan persyaratan memiliki prestasi kedisiplinan sebesar $98 \%$ per tahunnya. Status penyediaan rumah adalah kepemilikan dan bukan sewa. Type yang dibangun adalah type 21/60, dengan fasilitas yang ada adalah 1 kamar tidur, 1 kamar mandi, ruang tamu, dapur, listrik 1300 watt, pompa dragon. Khusus untuk keramik dan plester di bangun sendiri oleh masing-masing karyawan dengan dana subsidi perusahaan sebesar Rp 5 juta.

Fasilitas umum dan Fasilitas sosial belum ada, tapi di sekitar lingkungan perumahan sudah terdapat poliklinik (PUSKESMAS), sekolah, tempat ibadah, dan pasar. Sarana olah raga dan taman bermain anak belum tersedia.

Dalam proses pembangunan rumah untuk MBR ini, campur tangan pemerintah dalam meringankan beban MBR belum nampak dan peran serta masyarakat dalam pembangunan rumah ini juga belum nampak. Berdasarkan hasil tinjauan secara langsung, dapat disimpulkan bahwa lingkungan terkesan kurang rapi (tak terawat), air kurang bersih. Beberapa harapan dari masyarakat yang menghuni di perumahan tersebut yaitu krianya Pemerintah dapat membantu dalam hal penyediaan fasilitas umum, dan fasilitas sosial. Beberapa hal yang perlu dijadikan catatan: Nampak sekali kepedulian pihak perusahaan dalam mensejahterakan para pekerjanya khususnya pekerja yang penghasilannya di bawah Rp 2,5 juta, Tidak nampaknya campur tangan pemerintah dalam meringankan beban MBR, dan Meningkatkan kesejahteraan masyarakat di sekitar lingkungan perumahan dengan adanya bisnis-bisnis kecil yang bermunculan.

\section{Rumah Susun Kawasan Industri Manis, Tangerang}

Di Rumah Susun Kawasan Industri Manis, Tangerang, ini tanah disediakan dari PEMDA, dan diperuntukan untuk para pekerja industri di sekitar daerah tersebut. Type rumah sewa yang disediakan adalah type 18 dan 21, dengan fasilitas yang disediakan adalah dapur, kamar mandi, listrik 450 watt atau 900 watt. Pendanaan pembangunan gedung oleh PEMDA dan menjadi asset PEMDA. Fasilitas umum yang disediakan adalah parkir, tempat bermain dan sarana olah raga. Untuk poliklinik, pasar, sekolah, dan tempat ibadah terdapat di sekitar lingkungan rumah sewa. Pengelolaan dilakukan oleh PEMDA melalui UPT. Biaya sewa ditentukan berdasarkan PERDA. Berdasarkan pengamatan langsung, beberapa yang menjadi catatan penting: Rumah tinggal yang kurang layak, tidak terawat rapi dan kotor, Design rumah yang tidak pas (terlihat banyak jemuran pakaian di mana-mana), Pengelolaan yang tidak profesional, Tidak adanya pembinaan kedisiplinan bagi para penghuni. Pembinaan dilakukan karena rata-rata penghuni berasal dari golongan MBR dan terbiasa hidup dengan lingkungan yang kumuh, Meningkatnya kesejahteraan masyarakat di sekitar lingkungan perumahan dengan adanya bisnis-bisnis kecil yang bermunculan.

\section{Rumah Susun Sewa Muka Kuning, Batam (Jamsostek)}

Berbeda dengan rumah susun di atas, rumah sewa ini di bangun dengan menggunakan dana CSR JAMSOSTEK yang disisihkan dari laba per tahunnya. Prinsip dari JAMSOSTEK adalah dari anggota untuk anggota, artinya dana yang di himpun dari anggota di kelola dan hasilnya dapat dimanfaatkan oleh anggota yang berpenghasilan rendah. Untuk pembangunan Rumah Susun Muka Kuning - Batam, Pihak JAMSOSTEK mencari sendiri tanah dengan harga murah, HGB selama 30 tahun. Pembangunan rumah sewa ini diperuntukan khusus para pekerja industri yang belum menikah (single). Unit yang disediakan adalah ukuran type 27 termasuk ranjang, kasur, dan lemari di dalamnya (mirip tempat kos). Kamar mandi disediakan di dalam. Fasilitas yang disediakan adalah taman, parkir dan taman bermain. Untuk fasilitas lainnya terdapat di sekitar lingkungan tersebut, antara lain poliklinik, sekolah, tempat ibadah, dan pasar. Pengelolaan di lakukan oleh JAMSOSTEK, terdiri dari 
kebersihan, keamanan, parkir, perawatan gedung dan sampah. Penentuan biaya sewa dilakukan sendiri oleh pengelola. Kendala yang dihadapi oleh JAMSOSTEK saat ini adalah: Sulitnya mendapatkan harga tanah murah, sulitnya perijinan, dan kebutuhan konsultan teknik. Beberapa hal yang menjadi catatan penting setelah survei: Pengadaan rumah sewa dilakukan sendiri oleh JAMSOSTEK, Lingkungan yang sangat bersih, Design rumah yang sangat baik (tertata rapi dan sangat bersih), Tak nampak peran serta Pemerintah dan masyarakat dalam proses pembangunan rumah sewa di BATAM (terbukti pengurusan IMB yang masih belum selesai, padahal fisik bangunan sudah jadi), Meningkatnya kesejahteraan masyarakat di sekitar lingkungan perumahan dengan adanya bisnis-bisnis kecil yang bermunculan, Mitra yang terlibat hanya JAMSOSTEK

\section{Rumah Susun Sewa Pondok Bambu, Jakarta Timur}

Rumah Susun Sewa Pondok Bambu di bangun di atas tanah milik PEMDA DKI dan diperuntukan bagi warga DKI yang dapat menunjukkan KTP DKI. Setiap penghuni akan di evaluasi setiap dua tahun sekali guna perpanjangan sewa. Unit yang disediakan adalah type 24 termasuk dapur, kamar mandi. Fasilitas listrik tiap unit sebesar 900 watt. Pendanaan pembangunan rumah sewa didanai oleh PEMDA dan merupakan asset milik PEMDA. Penentuan tarif sewa berdasarkan PERDA. Fasilitas umum dan sosial yang disediakan adalah taman, parkir, dan taman bermain. Fasilitas yang memanfaatkan dari luar kompleks adalah poliklinik, pasar, tempat olah raga, sekolah dan tempat ibadah. Fasilitas yang belum tersedia adalah ruang bersama (Serba guna). Pengelolaan di lakukan oleh Dinas Perumahan meliputi kebersihan, keamanan, perawatan, administrasi, perparkiran dan sampah. Hal-hal yang menjadi catatan penting saat survei: Design yang kurang pas karena terjadi tampias saat hujan, terlihat banyaknya jemuran yang tidak teratur, Luas unit yang kurang, karena rata-rata di huni oleh 4 orang, Lingkungan yang kurang rapi, Tidak ada pembinaan bagi penghuni, Pengelolaan yang tidak profesional, Tempat tinggal dijadikan sebagai tempat usaha, Tidak melibatkan peran dunia usaha dan masyarakat dalam pembangunan dan pengelolaan rumah sewa, Mitra yang terlibat yaitu PEMDA DKI dan Dinas Perumahan

\section{Rumah Susun Cigugur Tengah, Cimahi}

Rumah Susun Cigugur Tengah, Cimahi di bangun di atas tanah milik PEMKOT yang diperuntukan khusus buruh yang telah berkeluarga dengan anak satu maksimal usia 9 tahun. Luas tiap unit seluas $21 \mathrm{M}^{2}$ dengan dapur dan kamar mandi di dalam, dan fasilitas listrik sebesar 900 watt tiap unit. Pembangunan rumah susun sewa ini di danai dari dana Hibah Pusat (Dinas PU). Dengan demikian maka kepemilikan tanah adalah milik PEMKOT, aset bangunan milik Pusat (PU). Fasilitas umum dan sosial di bangun dengan menggunakan dana hibah Propinsi, yang terdiri dari taman, parkir, taman bermain, tempat olah raga, dan tempat ibadah sedangkan untuk poliklinik, pasar, dan sekolah tersedia di sekitar lingkungan perumahan.

Pengelolaan dilakukan oleh PEMKOT meliputi kebersihan, keamanan, perawatan, administrasi, perparkiran, tagihan listrik, tagihan air, dan sampah. Untuk penentuan tarif sewa ditentukan berdasarkan Surat Keputusan Walikota. Hal-hal yang menjadi catatan penting saat survei yaitu: Tempat yang sangat tertata rapi, Pengelolaan profesional, Adanya pembinaan bagi para penghuni, Pendanaan pembangunan rumah susun sewa PEMKOT Cimahi lebih tertarik berasal dari dana hibah, Mitra yang terlibat adalah PEMKOT Cimahi, PEMDA (Propinsi) dan Pusat (PU).

\section{Perkembangan Kemitraan Pemerintah, Dunia Usaha, dan Masyarakat}

Secara garis besar, terdapat tiga hal yang harus segera diselesaikan pemerintah. Kesatu, membentuk kelembagaan baru yang mendukung pelaksanaan Kemitraan Pemerintah, Dunia Usaha, Dan Masyarakat; kedua, melakukan harmonisasi, reformasi dan revisi terhadap berbagai aturan yang saling bertentangan dan yang menghambat masuknya investasi; dan ketiga, meningkatkan kualitas sumber daya manusia. 
Untuk tugas pertama, pemerintah telah membentuk apa yang disebut dengan Komite Kebijakan Percepatan Penyediaan Infrastruktur (KKPPI) yang diketuai oleh Menteri Koordinator Perekonomian pada Mei 2005. Komite ini mempunyai tugas: (1) merumuskan strategi dalam rangka koordinasi pelaksanaan percepatan penyediaan infrastruktur; (2) mengkoordinasikan dan memantau pelaksanaan kebijakan percepatan penyediaan infrastruktur oleh Menteri Terkait dan Pemerintah Daerah; (3) merumuskan kebijakan pelaksanaan kewajiban pelayanan umum (Public Service Obligation) dalam percepatan penyediaan infrastruktur; (4) menetapkan upaya pemecahan berbagai permasalahan yang terkait dengan percepatan penyediaan infrastruktur.

Selain KKPPI, beberapa institusi pendukung dalam rangka Kemitraan Pemerintah, Dunia Usaha, Dan Masyarakat juga sedang dan telah dibentuk seperti: (1) Departemen Keuangan telah membentuk Pusat Pengelolaan Risiko Fiskal (Risk Management Unit) dan Badan Investasi Pemerintah; (2) Departemen Perhubungan, Departemen Pekerjaan Umum dan Departemen Energi dan Sumber Daya Mineral masing-masing telah membentuk Simpul Kemitraan Pemerintah; (3) Dunia Usaha, Dan Masyarakat (Kemitraan Pemerintah, Dunia Usaha, Dan Masyarakat Node); (4) Pemerintah juga membentuk Pusat Pengembangan Kemitraan Pemerintah, Dunia Usaha, dan Masyarakat (Kemitraan Pemerintah, Dunia Usaha, Dan Masyarakat Center).

Selanjutnya, pemerintah melakukan harmonisasi, reformasi dan revisi terhadadap berbagai aturan yang tidak market friendly, baik itu berbentuk Undang-Undang maupun Perda, termasuk aturan pelaksanaannya. Beberapa contoh kongkritnya adalah: (1) terbitnya Perpres Nomor 67 Tahun 2005 tentang Kerjasama Pemerintah dan Badan Usaha dalam Penyediaan Infrastruktur (sebagai revisi atas Kepres Nomor 7 Tahun 1998); (2) terbitnya Perpres Nomor 65 Tahun 2006 tentang Perubahan atas Perpres Nomor 36 Tahun 2005 tentang Pengadaan Tanah bagi Pelaksanaan Pembangunan untuk Kepentingan Umum; (3) Perpres Nomor 71 Tahun 2006 tentang Penugasan kepada PT PLN (Persero) untuk melakukan Percepatan Pembangunan Pembangkit Tenaga Listrik yang Menggunakan Batubara; (4) keluarnya Permenkeu Nomor 38 Tahun 2006 tentang Petunjuk Pelaksanaan Pengendalian dan Pengelolaan Risiko atas Penyediaan Infrastruktur; (5) banyaknya Perda yang direvisi dan dibatalkan, dan sebagainya.

Dan terakhir, pemerintah sangat membutuhkan SDM yang andal dan berintegritas dalam rangka menyukseskan pelaksanaan Kemitraan Pemerintah, Dunia Usaha, Dan Masyarakat di Indonesia. Andal dalam arti mempunyai kapasitas atau kompetensi tertentu untuk melaksanakan tugas dengan sangat baik. Tidak gagap ketika berhadapan dengan investor swasta membahas proyek yang dimintakan dukungan pemerintah atau tatkala melakukan analisis keuangan proyek maupun keuangan perusahaan investor. Berintegritas dalam arti tahan terhadap segala daya upaya para investor yang unfair agar proposal proyeknya disetujui untuk memperoleh dukungan pemerintah. Oleh karena itu, tidaklah berlebihan kalau untuk penempatan SDM di institusi pendukung Kemitraan Pemerintah, Dunia Usaha, Dan Masyarakat perlu dilakukan secara hati-hati. Praktek kemitraan antara Pemerintah dan Swasta sering juga disebut dengan istilah Kerjasama Pemerintah dan Swasta (KPS) atau Public Private Partnership (PPP/P3). Kemitraan ini dilakukan didasari oleh keterbatasan sumber daya Pemerintah daerah dalam pelaksanaan pembangunan dan pelayanan publik sementara tuntutan masyarakat terhadap kualitas pelayanan public semakin meningkat. Pola kemitraan dapat dilakukan dengan mempertimbangkan: (1) pelayanan atau proyek kegiatan tidak bisa dilakukan sendiri karena keterbatasan financial atau pengalaman Pemerintah; (2) mitra swasta bisa memberikan manfaat peningkatan kualitas atau level pelayanan yang lebih baik dari pada dilakukan sendiri oleh Pemerintah; (3) mitra swasta memungkinkan pelayanan atau proyek kegiatan bisa dilaksanakan lebih cepat daripada dilakukan sendiri oleh Pemerintah; (4) ada dukungan dari pengguna layanan untuk dilbatkannya swasta dalam kegiatan tersebut; (5) ada peluang kompetisi diantara mitra swasta yang prospektif. 


\section{PENUTUP}

Berdasarkan hasil dan pembahasan serta rekapitulasi di atas, dapat disimpulkan bahwa pembangunan rumah susun sewa yang dilakukan oleh Pemerintah, tidak melibatkan dunia usaha dan masyarakat. Belum nampak peran serta Pemerintah dalam pembangunan rumah susun sewa yang dilakukan oleh dunia usaha, Pengelolaan yang kurang profesional. Saran yang dapat diberikan pada penelitian tahap 1 ini, yaitu: Berdasarkan catatan saat survei, dalam pembangunan rumah susun sewa harus memperhatikan evaluasi kembali aturan main dalam pembangunan rumah susun sewa, artinya setiap rumah susun sewa yang akan dibangun, disarankan untuk dibuat dalam bentuk kemitraan minimal melibatkan dua pihak apakah antara pemerintah dengan dunia usaha, atau pemerintah dengan masyarakat, atau dunia usaha dengan masyarakat. Kendala pembangunan dan pengelolaan rumah susun sewa bagi dunia usaha dapat dijadikan peluang bagi pemerintah untuk ikut bermitra sebagai wujud partisipasi pemerintah dalam meringankan beban dunia usaha dan masyarakat dalam perolehan tanah, dan pengurusan ijin. Berdasarkan rekapitulasi kendala pembangunan dan pengelolaan rumah susun sewa, maka dapat dijadikan peluang bagi dunia usaha dan masyarakat dalam memperbaiki lingkungan, dan pengelolaan rumah susun sewa.

\section{DAFTAR PUSTAKA}

Ditjen Cipta Karya, Departemen Pekerjaan Umum. (2006). Evaluasi Peremajaan Kawasan

Kuswatojo, T. (2005). Perumahan dan Permukiman di Indonesia. Bandung: Penerbit ITB.

Parente, W.J. (2006). Public Private Partnerships. Workshop on Fundamental Principles and

Perguruan tinggi, tinggi dan masyarakat. Prosiding Seminar Perumahan Nasional Kebijakan Perumahan Formal Nasional dan Implementasinya di Kota Metropolitan, Universitas Pancasila, 16 Desember 2006, Jakarta.

Permukiman Perkotaan (Urban Renwal). Jakarta: Ditjen Cipta Karya.

Techniques for Effective Public Private Partnership in Indonesia, Jakarta.

Wijaksono, S. (2006). Kemitraan pembangunan perumahan antara pemerintah, 